\title{
METASTASE DE CARCINOMA COMPROMETENDO A CAUDA EQUINA
}

\author{
Ligia M. B. Coutinho* \\ Jose L. C. TeIXeIrA**
}

Os tumores intra-durais extra-medulares são geralmente neurinomas e meningeomas e, quando localizados intra-medularmente, são representados por astrocitomas e ependimomas, sendo raras as metástases medulares e de raízes nervosas, principalmente aquelas que constituem a cauda equina ${ }^{2,3}, 6$. A raridade de metástase medular e de raizes nervosas intra-dural é a razão desta publicação.

\section{OBSERVAÇÃO}

A.L., sexo masculino, 60 anos, hospitalizado em junho de 1971, com queixas de dor torácica direita. A radiografia de tórax mostrou massa tumoral no segmento posterior e apical direitos, invadindo a $3^{\text {a }}$ e $4^{a}$ costelas (Fig. 1); mediante biópsia pulmonar percutánea foi feito diagnóstico histopatológico de carcinoma brônquico do tipo indiferenciado de grandes células. Após dois meses de cobaltoterapia, o paciente teve alta hospitalar, permanecendo assintomático durante três meses, findos os quais começou a sentir dor localizada na regiāo lombar e face posterior da coxa, à esquerda, tendo sido novamente hospitalizado. A radiografia de tórax revelou regressão parcial das dimensões da neoplasia do lobo superior direito, não havendo sinais de metástases à distância nos ossos do esqueleto do tronco (Fig. 1). Nessa ocasião radiografias de coluna vertebral mostraram acentuada discopatia entre L5 e S1, com deslisamento posterior de L5; havia também discopatia degenerativa entre L2 e L3, com deslisamento posterior de L2. A sintomatologia agravou-se, havendo comprometimento do membro inferior direito e intensificacão da dor. o exame clinico-neurológico mostrou paciente caquético, com hipotrofia e hipotonia generalizadas, mais acentuadas nos membros inferiores. Reflexo patelar abolido e diminuição do reflexo aquileu à esquerda. Sinal de Lasègue a $15^{\circ}$, no membro inferior esquerdo. Havia comprometimento da sensibilidade superficial nos dermatômeros correspondentes a L4, L5 e S1, à direita e L3, L4, L5 e S1 à esquerda. A mielografia com contraste positivo (lipiodol) mostrou bloqueio total ao nivel do espaco L4-L5, sugerindo presenca de processo expansivo a esse nivel.

o paciente foi submetido a laminectomia lombar (L3, L4 e L5), tendo sido encontrado tumor localizado no espaço intradural, volumoso, friável, aderido à cauda equina, englobando-a totalmente, sendo dificil sua dissecção completa. O aspecto das raizes modificava-se à medida que se aproximava do tumor, aumentando seu calibre nesse ponto e seguindo, depois, com calibre normal. Foi retirado um fragmento de raiz, na área mais espessada, para exame histopatológico que demonstrou

* Auxiliar de Ensino no Departamento de Patologia da Fundação Faculdade de Medicina de Porto Alegre; ** Neurocirurgião do Hospital Nossa Senhora de Pompéia, Caxias do Sul. 


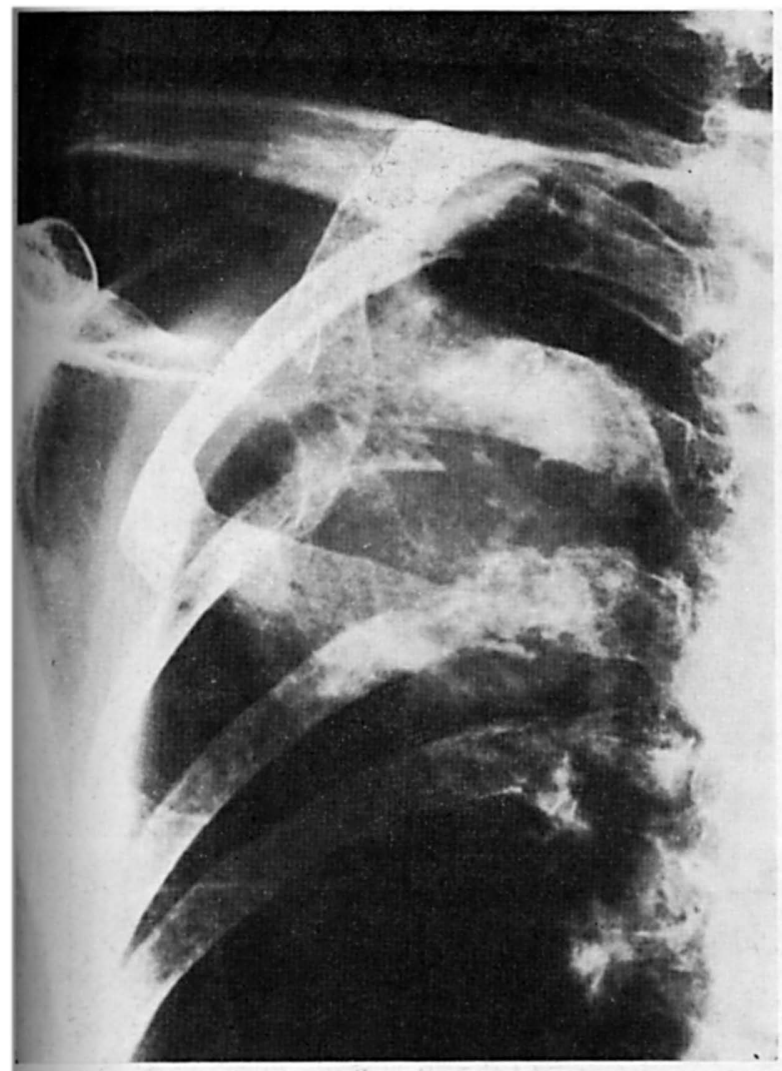

$\begin{aligned} \text { Fig. } 1- & \text { Caso A.L. } \\ & \text { Radiografia } \\ \text { de torax } & \text { mostrando } \\ & \text { massa } \\ & \text { tumoral } \\ & \text { ocupando os } \\ & \text { segmentos } \\ & \text { posterior } \\ & \text { apical } \\ & \text { direitos, } \\ & \text { com invasão } \\ & \text { das } s^{\circ} \text { e } 4^{\circ} \\ & \text { costelas. }\end{aligned}$

tratar-se de metástase de carcinoma indiferenciado, comprometendo raiz nervosa, estando as células neoplásicas localizadas nos espaços epi e perineurais (Fig. 2).

\section{COMENTARIOS}

Os tumores malignos invadem os nervos periféricos adjacentes por contiguidade ${ }^{5,7}$, podendo determinar compressão ou destruição dos mesmos ${ }^{5}$; entretanto, os nervos cranianos e as raízes nervosas apresentam comportamento diferente quando consideramos o comprometimento metastático.

As metástases intracranianas e raquianas podem se localizar em qualquer ponto do sistema nervoso, comprometendo mais frequentemente os hemisférios cerebrais e cerebelares, o tronco cerebral, a medula e raizes nervosas ${ }^{4}$. As metástases nos nervos cranianos e raizes ocorrem por disseminação liquórica de um processo metastático encefálico e, raramente, por via hemática $^{7}$. Como regra, qualquer nódulo de crescimento secundário comprometendo as raízes nervosas origina-se por disseminação liquórica de células neoplá- 

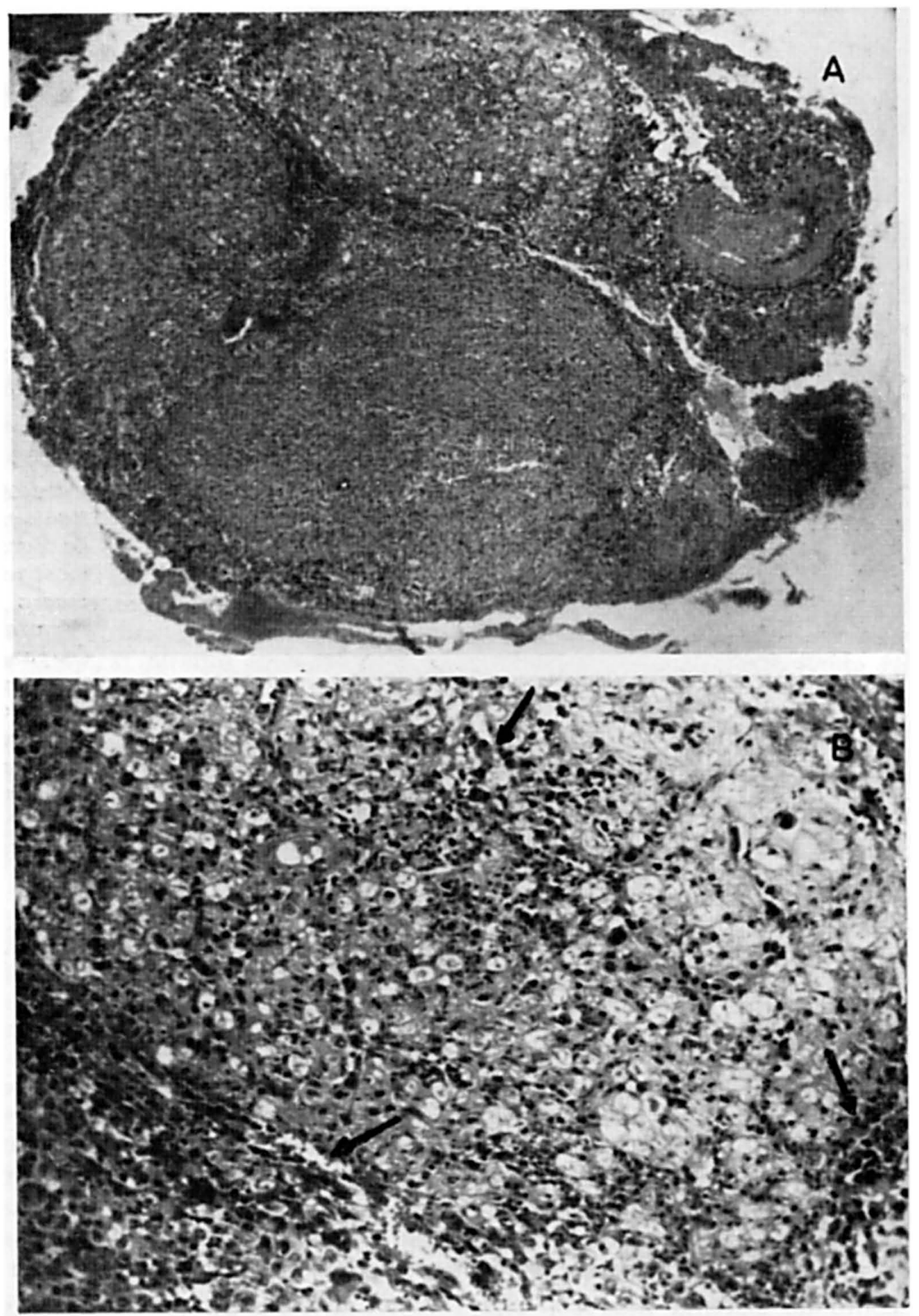

Fig. 2-Caso A.L. Na parte superior, aspecto microscópico da biópsia de uma raiz da cauda equina mostrando células neoplásicas de um carcinoma indiferenciado ocupando os espaços epi e perineurais (lupa, H.E.); na parte inferior, infiltrado neoplásico (10x, H.E.). 
sicas $^{7}$, mas pode haver casos em que as metástases são exclusivamente medulares ${ }^{2,6}$.

O comprometimento neoplásico secundário da medula é raro, apesar de serem comuns as metástases vertebrais, determinando compressão medular ${ }^{5}$. Entretanto, para Willis ${ }^{8}$, o crescimento metastático intra-dural, comprometendo a medula ou raízes nerovsas, não é incomum. $O$ pequeno número de casos estudados na literatura se deveria ao fato de que a medula somente é examinada quando há sinais clínicos de seu comprometimento. Mas esses sinais podem ser mascarados quando coexistem sintomas cerebrais ${ }^{8}$.

O primeiro caso de tumor metastático da medula foi descrito por Buchholz ${ }^{1}$, em 1898 , em paciente com carcinoma de mama, metástase cerebral e nódulos metastáticos em diversas alturas da medula. Ulteriormente, outros trabalhos foram publicados sobre metástase medular ${ }^{2,3,6}$. Cary ${ }^{2}$, em 1913, descreve metástase de corioepitelioma de útero, formando um cisto na porção final da medula e cauda equina.

\section{RESUMO}

É relatado um caso de paciente, de 60 anos, que apresentou tumor nos segmentos apical e posterior direitos, cujo diagnóstico histopatológico foi de carcinoma indiferenciado. O paciente foi submetido à cobaltoterapia, tendo melhorado por três meses, quando foi novamente hospitalizado por dor lombar. A mielografia com lipiodol mostrou processo expansivo intrarraqueano. Mediante cirurgia foi encontrado tumor intra-dural, englobando raizes nervosas. O diagnóstico microscópico foi de carcinoma indiferenciado infiltrando os espaços epi e peri-neurais.

\section{SUMMARY}

Metastatic carcinoma of the cauda equina: a case report

The case of a 60 year-old man who had an indifferenciated carcinoma in the lung is reported. He had recieved cobaltotherapy and had improved. After 3 months a lumbar pain had begun and the patient was hospitalized. A myelography with lipiodol demonstrated an intra-dural mass. At operation a big intra-dural tumor including the cauda equina was found. The microscopic examination revealed an undifferenciated carcinoma, that infiltrated the epi and peri-neural space.

\section{REFERENCIAS}

1. BUCHHOLZ - Casuistische Beitrag zur Kenntniss der Carcinome des Centralnervensystem. Mschz. Psych. Neurol. 4:183, 1898.

2. CARY, E. - Chorioepithelioma. Surg. Gynec. Obstet. 16:362, 1913.

3. CIRIO, L. - Sopra un carcinoma primitivo del pulmone con metastasi nel midollo spinale. Pathologica $22: 401,1930$. 
4. Escourolle, R. \& PORIER, J. - Manuel Élémentaire de Neuropathologie. Masson et Cie., Paris, 1971, p. 71.

5. HICKS, S. P. \& WARREN, S. - Introduction to Neuropathology. McGraw-Hill Book Co. Inc., Londres, 1950, p. 375.

6. PEQUignot, H.; GRIVAuX, M.; BONDUElle, M.; DelavierRe Ph. \& NAJMAN, A. - Metastases médullaires simulant un syndrome neurologique paranéoplasique, au cours d'un cancer bronchique méconnu a petites cellules. Sem. Hop. Paris 47:1139, 1971.

7. RUSSEL, D. S. \& RUBINSTEIN, L. J. - The Pathology of Tumors of the Nervous System. Edward Arnold Ltd., Londres, 1959, p. 222.

8. WILlis, R. A. - The Spread of Tumors in the Human Body. $2^{\text {a }}$ Edição. Butterworth \& Co. Ltd., Londres, 1952, p. 292.

Fundação Faculdade Católica de Medicina - Rua Sarmento Leite 245 - 90000 Porto Alegre, RS - Brasil. 